\title{
Finite Element Analysis Using Herrmann Formulation for Viscoelastic Materials
}

\author{
[Nitesh Kumar, Raviraja Adhikari, Devineni Anjaiah, Rajamani Marimuthu]
}

\begin{abstract}
The structural design and development of Solid rocket motor (SRM) is currently based on method of casting solid propellant grain into a metallic or composite casing. In general, SRM is subjected to diverse loading conditions during transportation, storage and firing, due to which cracks may be developed in solid propellants because of excessive loads. Finite element analyses (FEA) based on displacement method, were conducted in order to determine the integrity and the ultimate service life of solid rocket motors. The displacement based finite elements have the limitation of evaluating the distribution of stress and strain on the solid propellants which are viscoelastic in nature. In this paper, a finite element study based on Herrmann formulation is discussed to overcome this limitation in which 8node quadrilateral,9-node quadrilateral and 6-node triangular axisymmetric finite elements have been developed and analyzed for stress and strain distribution for head and mid segments of solid propellant rocket motor subjected to thermal loading. Results obtained from present study are compared to that obtained using MARC, commercial FEA software.

Keywords - Solid Rocket Motor, Herrmann Formulation, Thermal loads.
\end{abstract}

\section{Introduction}

Solid rocket motor (SRM) structural design is currently based on concept of a mechanically weak solid propellant grain cast into a stronger metallic or composite case. The outer case provides the essential structural resistance against service and operational loads, and the inner propellant grain's low strength is used for transmission of loads from grain surface to outer case. In general, solid rocket motors are subjected to diverse loading during transportation, storage and firing. It is well known that under these loading conditions, cracks can develop in solid propellants because of excessive loads. Therefore, in order to determine the integrity and the ultimate service life of solid rocket motors, studies were conducted to evaluate the

Nitesh Kumar

Manipal Institute of Technology,India

\section{Raviraja Adhikari}

Manipal Institute of Technology

India

Devineni Anjaiah

Manipal Institute of Technology,India

Rajamani Marimuthu,

Sci./Engr., SG, VSSC, Trivandrum. significance of the value and distribution of stress and strain [1]. The finite element method has the capability to deal with complex loading conditions, material behaviour and practical geometries. Commercial codes (viz., MARC, NASTRAN, NISA, ANSYS, etc.) are available to solve structural problems. Based on the nature of the final matrix equations the finite element methods are classified as Displacement Method [2], Force method [3] and mixed method [4]. The major structural components in rocket motor are: motor case, incompressible liner and propellant. The analysis of a viscoelastic structure may be reduced to elastic analysis by following the concept of Schapery [6] described in detail by Kanakaraju et al. [8].

Finite elements developed by displacement method have been the subject of extensive research for many years [2]. Shortcomings of this model are evident in situations involving nearly incompressible materials like solid propellants used in rocket motors. For incompressible materials (Poisson's ratio $\approx$ 0.5 ), the six components of strain are no longer independent, hence the principle of minimum potential energy and the corresponding displacement method experience locking, and the resulting solutions are erroneous [7]. Locking occurs when the element formulation is not sufficient for capturing the appropriate displacements. In these materials, the volumetric strain is nearly zero, hence using displacement method based finite elements results in zero displacement and the calculated stresses are under predicted and unreliable when low order displacement interpolations are used. Although, higher order interpolations, such as biquadratic interpolation or mesh refinement may be used, the displacement solution is generally not accurate. The solution to element locking in case of incompressibility is to break the strain field down to its fundamental components. In the case of any deformation, there are deviatoric and volumetric strain components. Deviatoric strains determine the shape change of the body and volumetric strains determine the volume change (dilatation) of the body. The volume change occurs due to a hydrostatic pressure. The trouble caused by the displacement based finite element formulation for the incompressible material can be understood by examining the familiar elasticity relationship,

$$
\begin{aligned}
& \frac{\text { Bulk uodulus }}{\text { Slusa uod ulus }}=\frac{\mathrm{K}}{\mathrm{G}}=\frac{2(1+v)}{3(1-2 v)} \\
& \text { where } K=\frac{E}{3(1-2 v)} \text { and } G=\frac{E}{2(1-2 v)}
\end{aligned}
$$

Where $\mathrm{E}$ is the Young's modulus and $v$ is the Poisson's ratio. For nearly incompressible materials, the Bulk modulus becomes large relative to the Shear modulus. In the limit, when the material is completely incompressible $(v=0.5)$, all 
hydrostatic deformations are precluded. In this limiting case it is therefore not possible to determine the complete state of stress from strain alone. Therefore special formulations are required to account for the hydrostatic deformations as well as to predict the actual state of stress for such materials. Thus, in this paper, a finite element study based on Herrmann formulation is discussed to overcome this limitation in which 8-node quadrilateral, 9-node quadrilateral and 6-node triangular axisymmetric finite elements have been developed and analyzed for stress and strain distribution for head and mid segments of solid propellant rocket motor subjected to thermal loading.

\section{Formulation}

In this paper, the Herrmann formulation code is written using visual $\mathrm{C}++$ language and validated with analytical solutions available in the literature. The elements developed are 8-node and 9-node quadrilaterals and 6-node triangular elements having linear pressure variation. The efficiency of these elements is examined by comparing the results obtained utilizing the MARC software package [14].

Energy expression for compressible material includes both strain energy and work done due to external forces. This formulation is modified in such a way that the volume of the body remains the same before and after loading. To bring this behaviour in the body the volumetric strain constraint is imposed. Mathematically volumetric strain is written as

$$
\frac{d V}{V}=0
$$

Assuming $\mathrm{V}=\mathrm{rz} \theta$ (for axisymmetric analysis)

Where $\mathrm{r}$ is the radius, $\mathrm{z}$ is the element height, and $\theta$ is the rotational angle.

From theory of elasticity, the stress strain relation is

$$
\delta_{x}\left|\sigma_{z}\right| \varepsilon_{g}-\left(\sigma_{z}, \sigma_{z}, \sigma_{g}\right) \frac{(1-2 v)}{\mathrm{E}}
$$

We get

$\varepsilon_{\mathrm{t}}\left|v_{c}\right| \varepsilon_{\theta}-\frac{\mathrm{P}}{\mathrm{K}}$

This can be rewritten as

$$
s_{v}-\frac{\mathrm{P}}{\mathrm{K}}-0
$$

Where $\mathrm{K}=\mathrm{E} / 3(1-2 v)$ is the bulk modulus, $\varepsilon_{\mathrm{v}}=\varepsilon_{\mathrm{r}}+\varepsilon_{\mathrm{z}}+\varepsilon_{\theta}$ is the volumetric strain given and $\mathrm{P}=\left(\sigma_{\mathrm{r}}+\sigma_{\mathrm{z}}+\sigma_{\theta}\right) / 3$

Writing the total potential energy with imposing $\varepsilon_{\mathrm{v}}=\mathrm{P} / \mathrm{K}$ as a constraint will make the volume of the body remain constant before and after loading as $\mathrm{K} \rightarrow \infty$.
The modified total potential for incompressible materials is given by

$$
\pi(u, P)=2 \pi\left[\frac{1}{2} \int_{A}^{\{\varepsilon\}^{T}}\left\{\frac{P}{2} \int_{A}\left(\varepsilon_{v}-\frac{P}{K}\right) r d A-\int_{A}\{u\}^{T}\{b\} r d A-\int_{S}\{u\}^{T}\{t\} r d S\right]-\sum_{i} u_{i} f_{i}\right.
$$

Strain and Stress vectors for axisymmetric body are given by

$$
\begin{aligned}
& \{\varepsilon\}=\left\{\varepsilon_{d}\right\}+\{1 / 3\} \varepsilon_{v} \\
& \{\sigma\}=\left\{\sigma_{d}\right\}+\{P\}
\end{aligned}
$$

Where $\left\{\varepsilon_{\mathrm{d}}\right\}$ is the deviatoric strain, and $\left\{\sigma_{\mathrm{d}}\right\}=\{\sigma-\mathrm{P}\}$.

Substituting for $\{\varepsilon\}$ and $\{\sigma\}$ in (5), the potential energy equation is modified as

$$
\begin{aligned}
\pi(u, P)= & 2 \pi\left[\frac{1}{2} \int_{A}\left\{\frac{1}{2} \int_{A} \frac{P_{d}^{2}}{K} r d A+\frac{1}{2} \int_{A}^{T} P\left\{\varepsilon_{V}-3 \alpha \Delta T\right\} r d A-\int_{A}\{u\}^{T}\{b\} r d A-\int_{S}\{u\}^{T}\{t\} r d S\right]\right. \\
& -\sum_{i} u_{i} f_{i}
\end{aligned}
$$

By substituting

$$
\begin{aligned}
& \{u\}=[N]\{q\} \\
& \left\{\varepsilon_{d}\right\}=\left[B_{d}\right]\{q\} \\
& \left\{\sigma_{d}\right\}=\left[C_{d}\right]\left[B_{d}\right]\{q\} \\
& P=\{H\}^{T}\{p\}
\end{aligned}
$$

And taking variation with respect to $u$ and $\mathrm{p}$ results in the following matrices

$$
\begin{aligned}
& {\left[\begin{array}{l}
{\left[K_{u u}\right]\left[K_{u p}\right]} \\
{\left[K_{p u}\right]\left[K_{p p}\right]}
\end{array}\right]\left\{\begin{array}{l}
\{q\} \\
\{p\}
\end{array}\right\}=\left\{\begin{array}{l}
\left\{F_{m}\right\} \\
\left\{F_{T}\right\}
\end{array}\right\}} \\
& \left\{F_{M}\right\}=2 \pi\left[\int_{A}[N]^{T}\{b\} r d A-\int_{1}[N]^{T}\{t\} d s\right] \\
& \left\{F_{T}\right\}=2 \pi \int_{A}[H]^{T} 3 \alpha \Delta \operatorname{TrdA} \\
& {\left[K_{u u}\right]=2 \pi \int_{A}\left[B_{d}\right]^{T}\left[C_{d}\right]\left[B_{d}\right] r d A} \\
& {\left[K_{p p}\right]=-2 \pi \int_{A} \frac{1}{K}\left[H_{p}\right]^{T}\left[H_{p}\right] r d A} \\
& {\left[K_{u p}\right]=-2 \pi \int_{A}\left[B_{v}\right]^{T}\left\{H_{p}\right\} r d A}
\end{aligned}
$$

Where $\{q\}$ - elemental displacement vector, $\{p\}$ - elemental hydrostatic pressure, $\{F M\}-$ load vector due to mechanical load, $\{\mathrm{FT}\}-$ load vector due to thermal load, $\alpha$ - linear coefficient of thermal expansion, $\Delta \mathrm{T}-$ difference in temperature, $[\mathrm{Kuu}]$ - element stiffness matrix corresponding to element displacement, [Kpp] - element stiffness matrix corresponding to element pressure, [Kup] - element stiffness matrix corresponding to the cross coefficient $\{q\}$ and $\{p\}$. If the displacement is assumed as quadratic variation then the 
pressure is assumed as bilinear variation. In general, the pressure variation is assumed one order lower than the displacement variation.

The displacements are used to get the elemental strains, stresses at the Gauss point and then it is extrapolated to the nodal points. The Gauss point stresses and strains are extrapolated to the nodal points by the bilinear extrapolation matrices as given in [Hinton et. al., 1975]. The stresses and strains for 8-node and 9-node quadrilateral elements are computed at $2 \times 2$ gauss points and extrapolated to 4 corner nodes of the element [Hinton et.al., 1975]. Stresses and strains at rest of the nodes are obtained by averaging the corner nodal values.

\section{Case study: Solid Rocket Motor Subjected to Thermal Load}

Solid rocket motor consists of a solid propellant grain which is viscoelastic in nature embedded into a stronger metallic or composite case with an insulator material and a liner between the case and the grain. The motors which are mainly utilized in defence and space technologies are generally stored for a long time and transported from one place to another before their ignition processes. During its lifetime the rocket motor may encounter various environmental effects, in particular temperature variations due to change in climate of storage or regions they are transported to. Since the mechanical properties of solid propellants are very sensitive to temperature changes, the effects of thermal loads on the performance of the rocket motor should be carefully examined before firing. Thermal loads during the standby position and pressure load during the operation may result in stress and strain values exceeding material capabilities [15], [17], hence leading to failure of the motor.

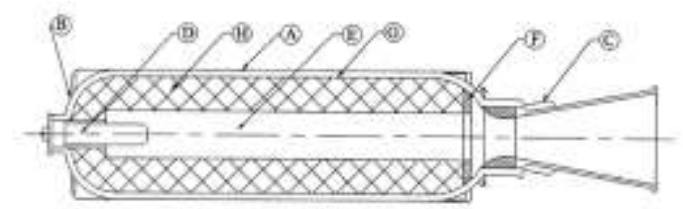

Figure 1: A typical rocket motor; A. Chamber; B. head end zone; C. nozzle; D. Igniter; E. Port; F. Inhibitor; G. Insulation; H. Propellant.

propellant grain segments are cast and cured separately at elevated temperatures for the required number of

days and then cooled to the room temperature before storage. Thermal stresses and strains are developed due to the cooling from the stress-free temperature to the storage temperature. [18]. In order to simulate the stress and strain of solid rocket motors (SRMs), a finite element analysis model was established. Due to difference in the coefficients of thermal expansion of the propellant and the casing, thermal stresses and strains are developed. Fig. 2 shows the finite element model of a typical SRM with discretisation and boundary conditions, which is analysed for applied thermal load, $\Delta \mathrm{T}=-35^{\circ} \mathrm{C}$ using the elements developed using Herrmann Formulation. The material properties are given in Table I.

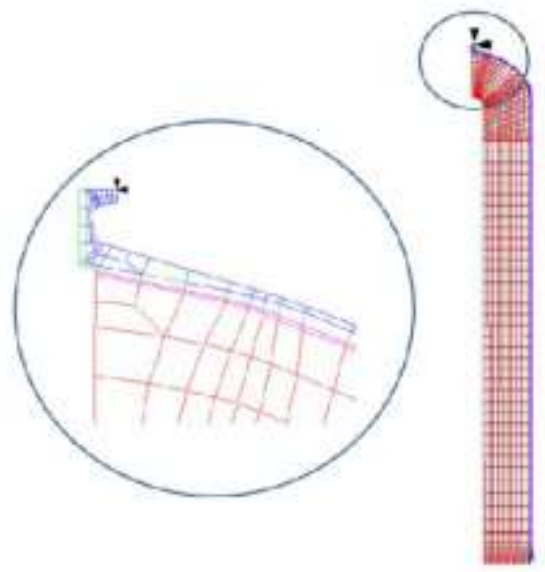

Figure 2: Finite element discretization and boundary condition for SRM subjected to thermal load

TABLE 1: MECHANICAL PROPERTIES OF THE SOLID PROPELLANT ROCKET MOTOR SUBJECTED TO THERMAL COOLING OF $-35^{\circ} \mathrm{C}$.

\begin{tabular}{|l|l|l|l|}
\hline Material & $\begin{array}{l}\text { Modulus } \\
(\mathbf{K g} / \mathbf{m m} 2)\end{array}$ & $\begin{array}{l}\text { Poisson's } \\
\text { Ratio }\end{array}$ & $\begin{array}{l}\text { Coefficient } \\
\text { of thermal } \\
\text { expansion } \\
\boldsymbol{\alpha}\left(/{ }^{\circ} \mathbf{C}\right)\end{array}$ \\
\hline Propellant & 0.20 & 0.499 & $8.6 \mathrm{E}-5$ \\
\hline Insulation & 1 & 0.5 & 0.0001 \\
\hline Casing & $2.08 \mathrm{E}+4$ & 0.3 & $1 \mathrm{E}-5$ \\
\hline
\end{tabular}

\section{Iv. Results and Discussion}

The results of the analysis are shown in the deformed and undeformed shapes (Fig. 3) and the contour plots (Fig. 4). The variation of resultant displacement, hoop strain at the inner port of propellant and the shear stress at the outer port is presented in path plots (Fig. 5 to Fig. 7). The results shows higher displacements at the head section of the rocket motor and at the lower end of the mid-section due to thermal shrinkage, which results in higher shear stresses. It is observed from the results obtained based on Herrmann formulation finite elements (present study) are in close agreement with those results obtained from MARC software. 
Proc. of the Intl. Conf. on Advances in Civil, Structural and Mechanical Engineering - ACSM 2015.

Copyright $\odot$ Institute of Research Engineers and Doctors, USA .All rights reserved.

ISBN: 978-1-63248-039-2 doi: 10.15224/ 978-1-63248-039-2-26
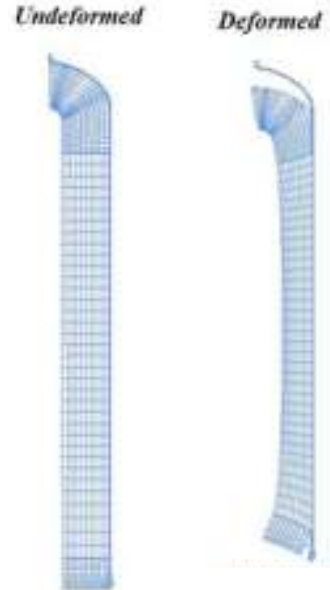

Figure 3: Undeformed shape and deformation due to thermal shrinkage

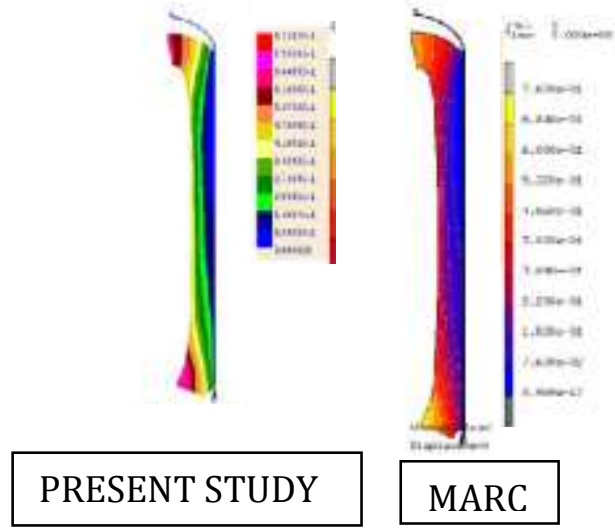

Figure 4: Resultant deformation contour comparison between the developed finite elements and MARC

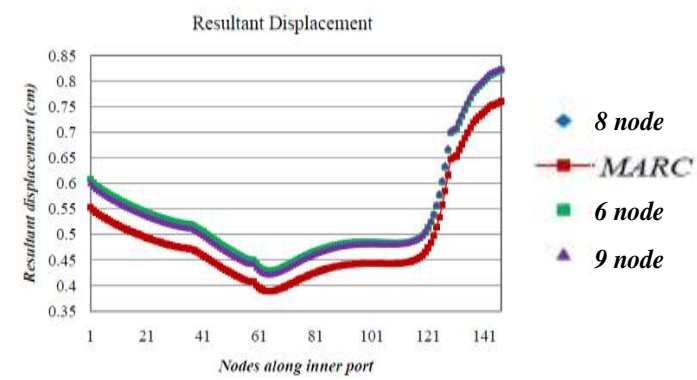

Figure 5: Variation Resultant displacement along the inner port of the propellant

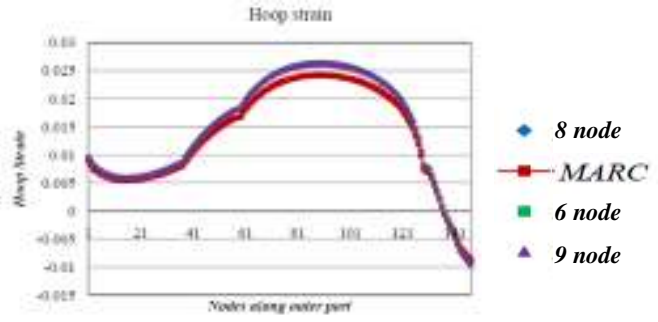

Figure 6: Variation of hoop strain along the inner port of the propellant

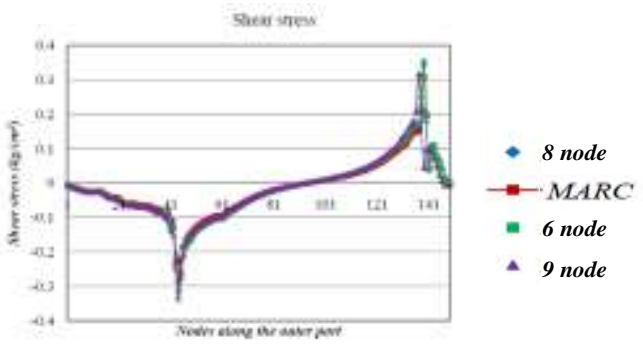

Figure 7: Variation of shear stress along the outer port of the propellant

\section{v. Conclusions.}

Axisymmetric finite elements based on Herrmann formulation has been developed and validated by comparing the results with the eight-node quadrilateral axisymmetric Hermann element of MARC. The results obtained from the present study are in good agreement with the results obtained using MARC. It should be noted that while using MARC software package, the casing material (which is compressible in nature) is idealized using the standard eight-node isoparametric quadrilateral axisymmetric element having two degrees of freedom $(\mathrm{w}, \mathrm{u})$, while the propellant grain (which is nearly incompressible in nature) is idealized using the Hermann element having three degrees of freedom $\left(\mathrm{w}, \mathrm{u}, \sigma_{\text {mean }}\right)$. Here $\sigma_{\text {mean }}$ is the hydrostatic pressure known as the mean pressure. For the present case bonded cylindrical solid propellant grain, the nodes at the interface should be connected using tying option to take care of the mismatch between two degrees of freedom of casing element 
and three degrees of freedom of nearly incompressible propellant element [18]. Present study does not require tying of the nodes. Whether the structure is made of compressible or nearly incompressible materials, the present study does not require tying option for the nodes at the interface. It can be concluded from the above-considered numerical problems that the present axisymmetric element can be used for examining the structural behaviour of rocket motors having nearly incompressible and incompressible materials.

\section{References}

[1] J.E Fitzerad, and W.L.Hufferd "Handbook for the Engineering Structural Analysis of Solid Propellant", CPIA publication 214, 1971

[2] O. C. Zienkiewicz., "The Finite Element Method", 3d ed. New York: McGraw-Hill, 1977.

[3] Walter. C. Hurty and Moshe. F. Rubinstein, "Dynamics of Structures",Prentice-Hall of India Private Limited, New Delhi, 1967.

[4] T. J. R. Hughes, "The Finite Element Method - Linear Static and Dynamic Finite Element Analysis", Englewood Cliffs, NJ: Prentice-Hall, 1987.

[5] E.H. Lee, "Stress analysis in Viscoelastic Bodies", Quarterly of Applied Mathematics, Vol.13, pp 183-190, 1955-1956.

[6] R.A. Schapary, "Two Simple Approximate Methods of Laplace Transform Inversion for Viscoelastic Stress Analysis", California Institute Technical Report, SM 61-23. Graduate Aeronautics Laboratories, 1961

[7] L.R. Herrmann, "Elasticity Equations for Incompressible and Nearly Incompressible Materials by a Variational Theorem", AIAA Journal, Vol.3, pp.1896-1900, 1965.

[8] K.Kanakaraju, B.Nageswara Rao and R.Marimuthu, "Hybrid StressDisplacement Finite Elements for Viscoelastic Analysis", In: FINITE ELEMENTS (Nikos Mastorakis, olga Martin Editors), Published by World Scientific and Engineering Academy and Society (WSEAS), pp. 43-53, 2007.

[9] Richard. H. Macneal and 1. Harder, "A Proposed Standard set of Problems to Test Finite Element Accuracy", Finite Elements in Analysis and Design, 1, 3-20. 1985.
[10] E. Hinton, F. C. Scott and R. E. Rickets, "Short Communications,Local Least Squares Stress Smoothing for Parabolic Isoparametric Elements", International Journal for Numerical Methods in Engineering, Vol. 9, 235256(1975)

[11] E. P. Kasper and R. L. Taylor, "Mixed-enhanced formulation for geometrically linear axisymmetric problems", International Journal for Numerical Methods in Engineering 2002: 53:2061-2086

[12] Cory Rupp, Micah Howard, and Gary Weickum, "Incompressible Mixed $(\mathrm{u} / \mathrm{p})$ Elements for the CAS FEM Code", Centre for Aerospace Structures, Department of Aerospace Engineering Sciences, University of Colorado at Boulder, Boulder, CO 80309, USA.

[13] M. R. Lajczok, "Effective Propellant Modulus Approach for Solid Rocket Motor Ignition Structural Analysis", Computer and Structures, Vol.56, No.1.pp.101-104, 1995.

[14] Nitesh Kumar, "Axisymmetric Finite Elements Using Herrmann Formulation for Viscoelastic Analysis", M Tech Thesis, Manipal Institute of Technology, Manipal University, 2010.

[15] S.Y. Ho, Viscoelastic response of solid rocket motor components for service life assessment, Journal of Materials Science 32 (1997) 5155-5161.

[16] D.T. Wadiak, P.M. Bond, N.A. Cyr, S. Fields, G.H. Ferguson, L.W Swenson, A finite element methodology to predict age-related mechanical property and structural performance changes in high performance polymers, International Journal for Numerical Methods in Engineering 29 (1990) 1159-1175.

[17] H.C. Yıldırım, S. Ozupek, "Structural assessment of a solid propellant rocket motor: Effects of aging and Damage" Aerospace Science and Technology 15 (2011) 635-641

[18] K. Renganathan, B. Nageswara Rao, M.K. Jana, "An efficient axisymmetric hybrid-stress-displacement formulation for compressible/nearly incompressible material", International Journal of Pressure Vessels and Piping 77 (2000) 651-667 